\title{
Epilepsy meets cancer: when, why, and what to do about it?
}

\author{
Weller, M ; Stupp, R ; Wick, W
}

\begin{abstract}
The lifetime risk of having epileptic seizures is profoundly increased in patients with cancer: about $20 \%$ of all patients with systemic cancer may develop brain metastases. These patients and those with primary brain tumours have a lifetime risk of epilepsy of 20-80\%. Moreover, exposure to chemotherapy or radiotherapy to the brain, cancer-related metabolic disturbances, stroke, and infection can provoke seizures. The management of epilepsy in patients with cancer includes diagnosis and treatment of the underlying cerebral pathological changes, secondary prophylaxis with antiepileptic drugs, and limiting of the effect of epilepsy and its treatment on the efficacy and tolerability of anticancer treatments, cognitive function, and quality of life. Because of the concern of drug-drug interactions, the pharmacological approach to epilepsy requires a multidisciplinary approach, specifically in a setting of rapidly increasing choices of agents both to treat cancer and cancer-associated epilepsy.
\end{abstract}

DOI: https://doi.org/10.1016/S1470-2045(12)70266-8

Posted at the Zurich Open Repository and Archive, University of Zurich

ZORA URL: https://doi.org/10.5167/uzh-64680

Journal Article

Accepted Version

Originally published at:

Weller, M; Stupp, R; Wick, W (2012). Epilepsy meets cancer: when, why, and what to do about it? Lancet Oncology, 13(9):e375-e382.

DOI: https://doi.org/10.1016/S1470-2045(12)70266-8 


\section{INVITED REVIEW}

\section{Epilepsy meets cancer: when, why, and what to do about it?}

Prof Dr Michael Weller, MD

Department of Neurology, University Hospital Zurich, Zurich, Switzerland

Prof Dr Roger Stupp, MD

Departments of Neurosurgery and Clinical Neurosciences, Centre Hospitalier

Universitaire Vaudois and University of Lausanne, Lausanne, Switzerland

Prof Dr Wolfgang Wick, MD

Department of Neurooncology, Neurology Clinic \& National Centre for Tumour Disease, University of Heidelberg, Germany

\section{Correspondence}

Prof. Dr. Michael Weller, Department of Neurology, University Hospital Zurich, Frauenklinikstrasse 26, CH-8091 Zurich, Tel. 4144255 5500, Fax 4144255 4507, EMail michael.weller@usz.ch

\section{Abbreviations}

AED, antiepileptic drugs; CNS, central nervous system; CRMP2, collapsin response mediator protein-2; EEG, electroencephalography; EI-AED, enzyme-inducing AED; 
GABA, $\gamma$-aminobutyric acid; HDAC, histone deacetylase; MRI, magnetic resonance imaging; SV2A, synaptic vesicle $2 \mathrm{~A}$.

\section{Contributor statement}

MW prepared the first draft of the manuscript. RS and WW reviewed and revised the manuscript. All authors approved the final version of the manuscript.

\section{Search Strategy and Selection Criteria section}

Data for this review were identified by searches of PubMed. References from relevant articles using the search terms „epilepsy, brain tumor, review“, which revealed 881 citations, „epilepsy brain tumor chemotherapy“ (753 citations), „epilepsy, drug interactions, tumor“ (114 citations), „partial epilepsy randomized controlled trial“ (614 citations) and „prognostic factors epilepsy glioma“ (30 citations) were considered. Articles were also identified through searches of the authors`own files. Only papers in English were reviewed. Data from controlled trials were regarded superior to data from uncontrolled series and the newest article was chosen, if multiple references to a similar topic were available. One abstract was included for novelty reasons. The final reference list was generated on the basis of originality and relevance to the broad scope of this review.

\section{SUMMARY}


The lifetime risk of suffering epileptic seizures is profoundly increased in cancer patients: approximately $20 \%$ of all patients with systemic cancer may develop brain metastases. These patients as well as patients with primary brain tumors carry a lifetime risk of epilepsy in the range of $20-80 \%$. Moreover, exposure to chemo- or radiotherapy to the brain as well as cancer-related metabolic disturbances, stroke and infection may provoke seizures. The management of epilepsy in cancer patients includes (i) diagnosis and treatment of the underlying cerebral pathology, (ii) secondary prophylaxis using antiepileptic drugs, and (iii) limiting the impact of epilepsy and its treatment on the efficacy and tolerability of anti-cancer treatments, cognitive function and quality of life. Because of the specific concern of drug drug interactions, the pharmacological approach to epilepsy requires a multidisciplinary approach, specifically in a setting of rapidly increasing choices of agents both to treat cancer and cancer-associated epilepsy. 


\section{Introduction}

Epileptic seizures are a potentially life-threatening symptom of structural or metabolic brain dysfunction. They are among the most common presenting features of patients with primary brain tumors. They are also a frequent complication in patients with disseminated cancer, mostly because of solid brain metastasis or leptomeningeal disease, but may also be caused by exposure to chemotherapy or radiotherapy to the brain, stroke, infection, or general disturbances e.g. of salt or liver metabolism associated with systemic cancer progression. This review focuses on the relevance of epilepsy for clinical oncology with specific consideration of the practical management of epilepsy in cancer patients as well as the increasingly complex interactions between the pharmacological approaches to cancer versus cancer-associated epilepsy. For specific aspects related to epilepsy and cancer, the reader is referred to contemporary review articles on epilepsy in primary brain tumor patients, ${ }^{1,2}$ drug drug interactions ${ }^{3,4}$ and drugresistant epilepsy. ${ }^{5}$

\section{Seizures and epilepsy: their nature and classification}

An epileptic seizure is most often a transient event caused by abnormal excessive or synchronous neuronal activity in the brain and can often, but not always, be recognized clinically by symptoms and signs of neurological dysfunction, most commonly altered consciousness and uncontrolled motor activity. As such, seizures can occur in the presence of a transitory precipitating factor, e.g., metabolic disturbance or exposure to a proconvulsive agent, including anti-cancer pharmaceutics, and are then a symptom of an underlying condition. Epilepsy, in contrast, is a disorder of the brain characterized by 
an enduring predisposition to generate epileptic seizures in the absence or presence of an underlying structural brain alteration. Accordingly, there are classifications of epileptic seizures as well as classifications of epileptic disorders. ${ }^{6}$ The distinction of seizures and epilepsy remains difficult in the context of brain tumors. In general, seizures can, as a symptom, herald the development of any structural brain disease and are then also best conceived as being symptomatic, e.g., of a brain tumor. Some patients suffer a single seizure that leads to the diagnosis of a benign tumor that can be resected, and the patient will never suffer a seizure again. In other patients, tumors remain stable with or without specific oncological treatment, but seizure control becomes a life-long therapeutic challenge.

It is estimated that approximately 50 million people worldwide suffer from some form of epilepsy, with a lifetime risk of one in 10 individuals to experience at least one seizure. In infants, seizures more often reflect an epileptic disorder without identifiable morphological brain pathology whereas in adults and in particular in the elderly seizures are commonly the first symptom of an underlying structural brain alteration. Cancer patients typically suffer either tonic-clonic generalized seizures that may be secondary to a focal seizure when they have structural brain lesions, which is more common, or not when they are triggered, e.g., by metabolic disturbances or exposure to proconvulsive agents, including anti-cancer pharmaceutics.

\section{Interfaces of epilepsy and cancer}


Cancer patients have a major risk of developing epileptic seizures in the course of their disease whereas patients with epilepsy do probably not exhibit an increased risk of cancer. Yet, it remains controversial whether anti-epileptic drug (AED) treatment may have an impact on the risk of developing cancer. Older AED like phenobarbital or phenytoin have been identified as tumor-promoting agents in animal studies whereas theoretical considerations led to the hypothesis that valproic acid may have tumorprotective properties (see below). ${ }^{7,8}$ Eventually, neither hypothesis has been confirmed to be of relevance in human cancer patients. Some rare hereditary diseases, mostly tuberous sclerosis, but also the neurofibromatoses and von Hippel Lindau disease, share epileptic seizures and tumors as disease characteristics. Here, type and location of tumors are likely to modulate the seizure risk. The life-time risk of brain tumor patients to experience epileptic seizures is in the range of $20-80 \%{ }^{1}$ It is higher in patients with primary brain tumors than in patients with brain metastasis. Seizures may occur in cancer patients in the absence of CNS involvement. In fact, even in the context of epilepsy in a cancer patient with a brain lesion, it must not be assumed that all epileptic seizures are caused by that lesion although this is a priori very likely. Alternative causes provoking or facilitating seizures including medications, metabolic disturbances, stroke or infection, need to be specifically considered, excluded or addressed, too. ${ }^{9}$

\section{Management of epilepsy in tumor patients: general principles}

The goals of epilepsy management include understanding its origin, treating its cause where possible, preventing further seizures, and limiting their sequelae. The initial workup of a suspected seizure requires an assessment of the circumstances of that episode and a thorough consideration of alternative diagnoses, mostly syncope, migraine and 
cerebral ischemia. History taking is commonly complemented by electroencephalography (EEG) and cardiological assessments, depending on the circumstances. At presentation of a first epileptic seizure, cerebral magnetic resonance imaging (MRI) is indicated and the preferred imaging method. This may lead to the diagnosis of a hitherto unknown primary brain tumor, metastatic presentation of a previously unknown systemic tumor (most frequently non-small cell lung cancer, but also breast cancer, melanoma or renal cell carcinoma), or spread to the central nervous system (CNS) in a known cancer patient. In general, effective tumor treatment consisting of surgical resection, radiotherapy, pharmacotherapy, or combinations thereof, is likely to contribute to seizure control in brain tumor patients. ${ }^{10}$ Brain tumorassociated epilepsy has commonly been considered more difficult to treat than other types of epilepsy, however, this perception is not supported by robust data. If the brain tumor is the accepted cause of epilepsy in brain tumor patients, then it will be difficult to control epilepsy if tumor cannot be controlled. Conversely, it has not been demonstrated that patients with stable brain tumors and epilepsy achieve seizure less often than other epilepsy patients, e.g., by pharmacotherapy.

Drug treatment-resistant epilepsy is commonly defined as a failure of adequate trials of two (or more) tolerated and appropriately dosed AED regimens to adequately control seizures. ${ }^{5,11}$ Resistance may be related to altered expression or activity of drug transporters at the blood brain barrier, limiting penetration to the tissue of seizure origin, altered expression or activity of the target molecules of AED, or underlying mechanisms of seizure generation that are not covered by the mode of action of currently available AED. Which of these reasons account for resistance to AED in brain tumor-associated epilepsy to what extent, remains controversial. Nevertheless, with the availability of new 
classes of AED which are better tolerated, resulting in better treatment compliance, seizures can be controlled with drug therapy either as single agents or in combination in the great majority of patients.

In addition to the specific treatment of the underlying brain tumor, pharmacotherapy is the mainstay of treating epilepsy in cancer patients (Table 1). The classification of drugs as first, second or third generation AED is inconsistently used in the literature. From a practical oncology perspective, the distinction of enzyme-inducing (EI) AED and non-EIAED is more relevant (see below). Many considerations support a thoughtful use of AED in patients with primary or metastatic brain tumors, including the possible resistance of the seizure disorder to AED, drug drug interactions, and unwanted effects from AED: rashes, drowsiness and cognitive alterations may severely affect quality of life. ${ }^{12}$ Unwanted effects from AED may also be more common in (brain) cancer patients than in patients with other etiologies of epilepsy. ${ }^{13}$ This has most likely multiple reasons, notably comedications such as steroids and chemotherapy, but also exposure to radiotherapy as well as effects of the tumor itself, and psychiatric comorbidity, notably depression. Of note, cognitive side effects from AED have to be weighed against cognitive deterioration induced by seizures, which can be severe and prolonged, too. If AED are indicated following the guidelines below, it is recommended to use non-EI-AED rather than EI-AED and to dose a single agent adequately high, that is to the edge of the recommended dose without unwanted effects, before moving to double or triple AED combinations, which are more difficult to monitor in terms of drug drug interactions, tolerability, safety, and efficacy. There is no evidence that specific AED are more active than others in brain tumor-associated epilepsy. Formal comparative trials of AED specifically in brain tumors have rarely been conducted, and the primary choice of agent 
varies among experts. The SANAD trials that had indicated preferential activity of lamotrigine in focal epilepsy and of valproic acid in generalized epilepsy ${ }^{14,15}$ cannot be simply extrapolated to patients with brain tumors. In the absence of randomized studies in the brain tumor population of patients with epilepsy, preferred drugs based on tolerability, interactions, and efficacy at present include valproic acid, levetiracetam, ${ }^{16,17}$ lamotrigine, ${ }^{18}$ and possibly lacosamide. ${ }^{19}$ Expression of synaptic vesicle protein $2 \mathrm{~A}$ (SV2A), the presumed target of levetiracetam, may predict response to the drug. ${ }^{20}$ Drug combinations that may be useful in cancer patients with epilepsy include valproic acid plus lamotrigine or levetiracetam or levetiracetam plus topiramate. ${ }^{18}$ The local delivery of AED via convection-enhanced delivery is feasible, but plays no role in clinical practice. ${ }^{21}$

\section{Are cancer patients at increased risk of epilepsy in the absence of CNS involvement?}

The most common cause of seizures in cancer patients is probably the development of solid brain metastases, ${ }^{9}$ but leptomeningeal involvement needs also consideration. Accordingly, the initial work-up of a first seizure in any cancer patient must include neuroimaging, preferably MRI to rule out brain metastases. Neuroimaging, however, may also reveal stroke or infectious complications, which may be more common in systemic cancer patients than in the general population. The work-up may also include a lumbar puncture to analyze the cerebrospinal fluid for malignant cells, microorganisms, lactate and protein. Moreover, various cancer chemotherapy regimens may provoke seizures in a minority of cancer patients, e.g., high-dose chemotherapy with ifosfamide or methotrexate. ${ }^{9}$ Chemotherapy-related seizures occurring in the absence of brain metastases usually do not necessitate long-term AED treatment. Rare syndromes of 
paraneoplastic disorders with epilepsy have been linked to autoantibodies against ion channels and neurotransmitter receptors, and some of these are tumor-associated, e.g., antibodies to the N-methyl-D-aspartate (NMDA) type of glutamate receptors in patients with teratoma. ${ }^{22}$

\section{Epilepsy in systemic cancer patients with CNS involvement}

Solid brain metastases seem to cause seizures less frequently than primary brain tumors, which may be explained by their less infiltrative growth and their inability to biochemically modulate neuronal excitability. New-onset seizures in patients with known brain metastases may indicate hemorrhage into a metastatic lesion, notably in metastatic melanoma patients, or tumor progression with associated edema. Patients undergoing resection of single or multiple brain metastases do not require primary seizure prophylaxis before and after surgery if they have never suffered a seizure.

\section{Epilepsy in primary brain tumor patients}

The life-time incidence of epileptic seizures in patients with primary brain tumors varies by diagnosis, age and literature source and is estimated in the range of $20-80 \%$. The incidence is relatively lower in some of the most malignant brain tumors such as glioblastoma and primary central nervous system (CNS) lymphoma, but higher in some more benign, but still infiltrative lesions such as World Health Organization (WHO) grade II diffuse gliomas. The reasons for these differences are multifold, but remain somewhat speculative. Typical features attributed a high seizure risk include location in the temporal lobe and cortical as opposed to white matter involvement. In this regard, oligodendroglial tumors are often located at the interface between cortex and white 
matter and cause seizures frequently whereas primary CNS lymphomas are more commonly growing in the white matter and are usually not diagnosed because of an epileptic seizure. In some types of brain tumors such as dysembryoplastic neuroepithelial tumors, the natural course of the tumor is very benign, but the severity of epilepsy dictates the necessity for surgical intervention. ${ }^{23}$ In such instances, surgery should be performed at centers specialized in epilepsy surgery. In low-grade gliomas, complete resection, shorter seizure history $<1$ year, seizures other than focal seizures, and previous seizure response to pharmacotherapy were associated with better seizure control after surgery. ${ }^{24}$ In general, surgical tumor resection may greatly contribute to the reduction of seizure frequency and severity in patients with brain tumor-associated epilepsy. Beyond surgical resection, ${ }^{25,26}$ other anti-tumor treatments such as radiotherapy and chemotherapy may improve seizure control e.g. in patients with lowgrade gliomas. ${ }^{27}$ Some patients treated with temozolomide chemotherapy report improvement of seizure frequency well before any objective tumor regression is demonstrated by neuroimaging. Another compelling example of a nonsurgical anti-tumor treatment that helped to improve epilepsy in more than half of patients was recently provided by the introduction of the mTOR inhibitor, everolimus, as an experimental agent to inhibit the growth of subependymal giant cell astrocytomas in patients with tuberous sclerosis. ${ }^{28}$ The rationale for everolimus is enhanced mTOR activity resulting from lack of upstream control exerted by the tuberin/harmartin complex.

The proximate causes of why brain tumor patients suffer seizures at all and whether seizures in these patients have a different cause compared with other structural neurological brain disease such as multiple sclerosis or stroke have remained obscure. Little research has been done to specifically address this issue, as reviewed in depth 
recently. ${ }^{2}$ Tumor location in proximity to cortical structures likely plays a role because neurons are considered the source of seizures. Ischemia of surrounding brain induced by tumor-associated changes in perfusion and the blood vessel network may contribute to seizure activity. Certain histological subtypes of primary brain tumors take up or release neurotransmitters and may thereby modulate neuronal excitability. Notably excessive glutamate levels have been proposed to mediate neuronal receptordependent excitation triggering seizure activity. Accordingly, it has been proposed that glioblastoma patients suffering seizures have lower glutamine synthase levels than seizure-free patients. ${ }^{29}$ Glutamine synthase consumes ammonia and glutamate to generate glutamine. Moreover, tumor cells may also express ion channels and neurotransmitter receptors and the controversial discussion on the cellular origin of primary brain tumors with the possible link to neural progenitor cells have supported the hypothesis that some tumor cells themselves may generate electrical activity promoting seizures. ${ }^{30-32}$ Conversely, not only the tumor, but also the type of host response including inflammatory changes may determine the likelihood of developing symptomatic epilepsy. ${ }^{33}$ More recently, indoleamine 2,3-dioxygenase is a cytokine-inducible enzyme that participates in tryptophan and serotonin metabolism has been associated with seizure activity in inflammation. ${ }^{34}$ Due to its intimate role in different tumors including brain tumors, ${ }^{35}$ indoleamine 2,3-dioxygenase-mediated tryptophan catabolism may also be involved in seizures in brain tumor patients. Whether it is protective or promoting seizure activity remains to be shown, but would allow for an innovative treatment approach.

\section{Do AED exhibit intrinsic anti-tumor properties?}


Intrinsic antitumor activity of certain AED and synergy with chemotherapy or radiotherapy have been suggested in some, but not all studies. For instance, phenytoin has been attributed anti-mitotic and anti-invasive properties, and valproic acid has been suggested to induce cell differentiation, growth arrest, apoptosis, autophagy, and these effects were proposed to be mediated by histone deacetylase (HDAC) inhibitory properties. ${ }^{36-40}$ These issues were most often addressed in the context of gliomas, given the high need for AED treatment in this patient population. We did not observe cytotoxic or antiproliferative effects of either carbamazepine, phenytoin or valproic acid in cultured glioma cells at concentrations likely to be achieved in vivo. ${ }^{41}$ Yet, valproic acid alone delayed growth in medulloblastoma xenograft models in severe combined immunodeficiency mice in the apparent absence of relevant systemic toxicity, ${ }^{37}$ but because of differences in valproic acid metabolism of valproic acid in mouse and man, these interesting observations in mice are difficult to extrapolate to human patients. Moreover, valproic acid when combined with the DNA (cytosine-5) methyltransferase inhibitor 5-aza-2'-deoxycytidine reduced the incidence of medulloblastomas and rhabdomyosarcomas in heterozygous Patched 1 knockout mice. ${ }^{38}$ The same combination induced expression of the candidate tumor antigen NY-ESO-1 in cultured glioma cells. ${ }^{39}$ If AED act via HDAC inhibition only to potentially inhibit tumor growth when administered alone, their antitumor activity can be predicted to be low, given that much more powerful HDAC inhibitors have shown rather limited single agent activity in human cancer patients. ${ }^{42}$

\section{Interactions of cancer therapy and AED: tolerability}


Pharmacokinetic as opposed to pharmacodynamic interactions of AED and various anticancer drugs are the most important area to consider for the general oncologist at the interface between cancer care and epilepsy. ${ }^{3,4}$ Although many AED are metabolized in the liver, only certain agents like phenytoin, carbamazepine and derivatives, and phenobarbital, induce CYP450-dependent hepatic enzymes and thus increase their own metabolism and more importantly, the metabolism and degradation of many commonly used cytotoxic agents (Table 2). Most new AED are neutral in this regard whereas valproic acid may inhibit metabolism and consequently augment half-life and toxicity of concomitant medications. For the design of clinical trials, also outside neurooncology, this calls for groups separated for the use of EI-AED or non-EI-AED, since maximal tolerated doses as well as effective doses may be relevantly different. Alternatively, many new trials per se exclude patients on EI-AED. The spectrum of AED as well as the spectrum of anti-cancer agents is steadily increasing. There are various websites beyond Pubmed or Medline where information on such interactions can be retrieved. These require regular up-dating. Importantly, the risk of using such EI-AED does not only include the risk of delivering expensive, but necessarily ineffective medical cancer therapy, but also a sudden increase in toxicity and loss of tolerability when such EI-AED are withdrawn and replaced by non-EI-AED. Thus, special attention to drug drug interactions is required not only when implementing, but also when tapering AED. Conversely, the enzyme-inhibiting effect of valproic acid appears clinically of lesser importance, although increased myelosuppression may develop in patients receiving nitrosoureas or cisplatinum-based chemotherapy or temozolomide concomitantly with valproic acid. ${ }^{43,44}$ There are also safety concerns regarding the choice of AED in cancer patients beyond drug-drug interactions. Various neurosurgeons fear an increased risk of 
peri-operative bleeding complications in valproic acid-treated brain tumor patients, although this is not supported by the literature. ${ }^{45,46}$ The risk of severe skin toxicity is increased when patients are treated with phenytoin or carbamazepine or oxcarbazepine not only in combination with procarbazine, but also with radiotherapy. ${ }^{47}$ Finally, EI-AED decrease the bioavailability of steroids, necessitating careful clinical monitoring when ElAED are newly introduced in steroid-dependent brain tumor patients. Conversely, when EI-AED are replaced by non-EI-AED, it should be assessed whether steroid doses can be lowered. Based on these considerations and the unfavorable safety profile of these drugs regarding cognitive function, we propose to select a priori newer AED, which are devoid of such interactions.

\section{Interactions of cancer therapy and AED: efficacy and survival}

Because of the enzyme-inducing activity described above, older AED such as phenytoin, phenobarbital or carbamazepine may enhance the metabolism of many commonly administered chemotherapy agents and thus decrease their efficacy (Table 2). Accordingly, there is now a trend to favor non-EI-AED for cancer patients, in order to allow effectively the administration of chemotherapy and targeted agents that often show increased hepatic metabolism in EI-AED-treated patients. Conversely, it has not been demonstrated that the enzyme inhibitory activity of valproic acid results in clinically relevant increases in anti-cancer drug levels and that this increases their activity through a pharmacokinetic mechanism.

Intrinsic anti-tumor activities (see above) or pharmacodynamic potentiation of radiotherapy or chemotherapy have been proposed to be mediated by some AED. However, there is only limited data from in vitro studies indicating additive or synergistic 
activity of AED with cancer therapeutics. For instance, we did not observe a modulation of the cytotoxic or antiproliferative effects of several anti-cancer drugs, including vincristine, cytarabine, doxorubicin, cisplatin, 3-bis-(2-chloroethyl)-1-nitrosourea (BCNU) and teniposide (VM26), by either carbamazepine, phenytoin or valproic acid in cultured glioma cells at concentrations likely to be achieved in vivo. ${ }^{41}$ More recently, levetiracetam has been proposed to sensitize glioblastoma cells to temozolomide via suppression of $\mathrm{O}^{6}$-methylguanine-DNA-methyltransferase expression, ${ }^{48}$ thus targeting one of the major resistance pathways of alkylating agent chemotherapy. ${ }^{49}$ Since the life-time risks of glioblastoma patients to experience epileptic seizures as well as AED-associated toxicity are considerable, and since these patients are now commonly exposed to chemotherapy, there has traditionally been significant interest in the choice of AED in glioblastoma. A retrospective analysis of three trials performed by the North Central Cancer Treatment Group indicated a possible association of EI-AED use, but not of seizure history, with a favorable outcome in glioblastoma patients. ${ }^{50}$ Yet, the implications of this observation remain unclear in that the chemotherapy regimens used in these trials are not considered active. ${ }^{51}$ Accordingly, we retrospectively assessed a potential predictive association with outcome of AED use within the pivotal trial of radiotherapy alone versus radiotherapy plus concomitant and adjuvant temozolomide for newly diagnosed glioblastoma that was conducted by the European Organization for Research and Treatment of Cancer and the National Cancer Institute of Canada Clinical Trials Group. ${ }^{52}$ We identified 387 patients (68\% of all patients) who received any $A E D ; 110$ patients (28\% of those receiving $A E D)$ were prescribed exclusively non-EI-AED, mostly valproic acid, while the others received at least one EI$A E D$, either phenytoin, carbamazepine, oxcarbazepine, or phenobarbital. We specifically 
compared three groups of patients, those without AED, those treated with valproic acid alone, and those treated with EI-AED only. After controlling for potentially confounding factors, we still observed a significant increase in overall survival of patients treated with valproic acid in the experimental arm, but not in the radiotherapy arm, suggesting a specific interaction between valproic acid and temozolomide chemotherapy. This association remains after adjusting for potentially confounding factors and inbalances. Moreover, hematological toxicity in patients treated with chemoradiotherapy and valproic acid was increased. ${ }^{44}$ Nevertheless, our analysis has some limitations and should be interpreted with caution. The data were generated from an unplanned and insufficiently powered retrospective analysis with limited statistical power. AED use for the purpose of this analysis refers only to baseline use, that is, at study entry when patients were treated with radiotherapy with or without temozolomide chemotherapy, but no detailed data on further AED treatment were collected during the course of the study. The reason for the prescription of AED was not recorded, thus, patients may have been receiving AED because of a seizure at disease presentation or as primary prophylaxis during the peri- and postoperative phase. We assume that only a minority of patients was maintained on valproic acid throughout the planned six cycles of adjuvant temozolomide, raising the possibility that any sensitization to chemoradiotherapy by valproic acid might have been underestimated here. At least two mechanisms for this improved efficacy of temozolomide chemotherapy conferred by comedication with valproic acid may be considered. Temozolomide is a prodrug converted to 3-methyl(triazen-1-yl)imidazole-4-carboxamide which is either hydrolyzed or unchanged prior to excretion. No effect of phenytoin, carbamazepine, or phenobarbital on temozolomide clearance has been observed whereas valproic acid decreased its clearance by $5 \%$ 
(http://www.temodar.com ). To some extent, the increased hematological toxicity during adjuvant temozolomide chemotherapy with valproic acid may thus be related to an increased bioavailability of temozolomide. Yet, thrombocytopenia is not an uncommon side effect in patients treated with valproic acid alone. Moreover, the negative result for temozolomide dose intensification in the Radiation Therapy Oncology Group 0525 trial $^{53}$ strongly argues against the hypothesis that valproic acid simply increases the biologically active dose of temozolomide. Increased hematological toxicity has previously been observed when glioma patients were co-treated with valproic acid and nitrosourea-based chemotherapy, but survival data by AED use were not reported. ${ }^{43}$ Alternatively, our observation may lend support to the notion that HDAC inhibitory properties of valproic acid sensitize glioma cells for temozolomide. The $\mathrm{EC}_{50}$ for valproic acid-induced HDAC inhibition is $500 \mu \mathrm{M},{ }^{36}$ which probably exceeds the clinically achieved plasma concentrations. Yet, some glioblastoma patients reoperated after exposure to valproic acid exhibit evidence of HDAC inhibition. ${ }^{54} \mathrm{~A}$ prolonged survival of 14 months versus 11 months was observed in glioblastoma patients treated with adjuvant CCNU who received a non-EI-AED, mainly valproic acid, compared with patients on EI-AED, mainly carbamazepine. ${ }^{55} \mathrm{~A}$ phase I dose escalation trial of valproic acid combined with 5-fluorouracil, epirubicin, and cyclophosphamide confirmed that HDAC inhibition could be achieved in vivo. ${ }^{56}$ Yet, a phase I trial exploring valproic acid plus dacarbazine/interferon- $\alpha$ chemoimmunotherapy in metastatic melanoma showed only moderate tolerability, but no indication of enhanced activity. ${ }^{57}$ Exploratory trials using HDAC inhibitors more potent than valproic acid such as vorinostat in combination with temozolomide radiochemotherapy may provide further support for this hypothesis. 
Selective HDAC inhibitors might also have a preferred tolerability profile compared with valproic acid, which induces weight gain, alopecia and tremor in some patients (Table 1). In any case, this analysis from a randomized phase III trial supports the view that the choice of AED in brain tumor patients may affect survival. ${ }^{44}$

\section{Frequently asked questions (FAQ) regarding epilepsy and cancer}

The interface between cancer and epilepsy currently provides an area of many interesting observations, active clinical and laboratory research, and opportunities to improve quality of life and outcome in cancer patients. Yet, there are at the same time many questions that arise in daily clinical practice and for many of which there are no answers that could be based on several or even one adequate clinical trial.

Table 3 summarizes some of these classical questions (and answers). Improved cancer therapy, as well as early and regular prenatal care, allow normal pregnancies and pregnant women with cancer to deliver healthy babies. Here it may be important to attempt decreasing pharmacotherapy to monotherapy and to taper doses of AED to the lowest possible level. There is no anticonvulsant of choice; however, the best safety data are available for lamotrigine. ${ }^{58}$ In women who have not had a seizure for $2-5$ years, an attempt at complete AED withdrawal is warranted. Patients should be offered preconceptual genetic counseling.

Almost a quarter of people diagnosed with epilepsy are $>60$ years of age. Underlying factors are discovered in a greater proportion than in younger patients, including cerebrovascular disease, dementia, trauma and tumors. Treatment should be kept at the lowest effective dose since there is an increased risk of side effects and idiosyncratic reactions. ${ }^{59}$ There is an increased risk of pharmacological interactions due to 
polypharmacy. The likelihood and severity of adverse reactions is increased. Since longterm AED treatment is considered an independent risk factor for osteoporosis, calcium and vitamine D supplements should be considered with AED treatment in the elderly. Further, epilepsy is associated with an increased risk of mental health disorders, such as anxiety, depression and suicidal thoughts. ${ }^{60}$

\section{Conclusions}

Recognition and secondary prophylaxis of seizures and epilepsy in cancer patients are a major challenge that commonly requires a multidisciplinary approach. The major goals, freedom from seizures, achieving seizure control with an acceptable safety and tolerability of $A E D$, and achieving seizure control without interfering with the efficacy of cancer treatment, can often be achieved, however, careful monitoring and thoughtful clinical decision making are required.

\section{Conflicts of Interest}

MW has received honoraria for lectures or advisory board participation from Antisense Pharma, Magforce, Merck \& Co, Merck Serono, and Roche, as well as research support from Merck \& Co. and Merck Serono.

RS has received honoraria for lectures or consultancy or both from Merck \& Co, Roche, and Celgene. RS is a principal investigator on a Merck-Serono/EORTC-sponsored clinical trial investigating cilengitide in glioblastoma, and has served as an uncompensated advisor to Novocure Ltd. 
WW has received honoraria for lectures or advisory board participation from Magforce, Merck \& Co, Merck Serono, and Roche, as well as research support from Apogenix, Boehringer Ingelheim, Eli Lilly, and Merck \& Co. 


\section{References}

1. Van Breemen MS, Wilms EB, Vecht CJ. Epilepsy in patients with brain tumours: epidemiology, mechanisms, and management. Lancet Neurol 2007;6:42130.

2. De Groot M, Reijneveld JC, Aronica E, Heimans JJ. Epilepsy in patients with a brain tumour: focal epilepsy requires focused treatment. Brain 2011 Dec $13 .$.

3. Patsalos PN, Perucca E. Clinically important drug interactions in epilepsy: interactions between antiepileptic drugs and other drugs. Lancet Neurol 2003;2:47381.

4. Yap KY, Chui WK, Chan A. Drug interactions between chemotherapeutic regimens and antiepileptics. Clin Ther 2008;30:1385407.

5. Kwan P, Schachter SC, Brodie MJ. Drug-resistant epilepsy. N Engl J Med 2011;365:91926.

6. Berg AT, Berkovic SF, Brodie MJ, et al. Revised terminology and concepts for organization of seizures and epilepsies: report of the ILAE Commission on Classification and Terminology, 2005-2009. Epilepsia 2010;51:67685.

7. Singh G, Hernaiz Driever P, Sander JW. Cancer risk in people with epilepsy: the role of antiepileptic drugs. Brain 2005;128:717.

8. Singh G, Bell GS, Hernaiz-Driever P, Sander JW. Cancer risk in people with epilepsy using valproate-sodium. Acta Neurol Scand 2012;125:234240.

9. Singh G, Rees JH, Sander JW. Seizures and epilepsy in oncological practice: causes, course, mechanisms and treatment. J Neurol Neurosurg Psychiatry 2007;78:3429.

10. Wick W, Menn O, Meisner C, et al. Pharmacotherapy of epileptic seizures in glioma patients: who, when, why and how long? Onkologie 2005;28:3916. 
11. Kwan P, Arzimanoglou A, Berg AT, et al. Definition of drug resistant epilepsy: consensus proposal by the ad hoc Task Force of the ILAE Comission on Therapeutic Strategies. Epilepsia 2010;51:106977.

12. Klein M, Engelberts $\mathrm{NH}$, van der Ploeg HM, et al. Epilepsy in low-grade gliomas: the impact on cognitive function and quality of life. Ann Neurol 2003;43:51420.

13. Glantz MJ, Cole BF, Forsyth PA, et al. Practice parameter: anticonvulsant prophylaxis in patients with newly diagnosed brain tumors: report of the Quality Standards Subcommittee of the American Academy of Neurology. Neurology 2000;54:188693.

14. Marson AG, Al-Kharusi AM, Alwaidh M, et al. The SANAD study of effectiveness of carbamazepine, gabapentin, lamotrigine, oxcarbazepine, or topiramate for treatment of partial epilepsy: an unblinded randomised controlled trial. Lancet 2007a;369:100015.

15. Marson AG, Al-Kharusi AM, Alwaidh M, et al. The SANAD study of effectiveness of valproate, lamotrigine, or topiramate for generalised and unclassifiable epilepsy: an unblinded randomised controlled trial. Lancet 2007;369:101626.

16. Rosati A, Buttolo L, Stefini R, Todeschini A, Cenzato M, Padovani A. Efficacy and safety oflevetiracetam in patients with glioma. A clinical prospective study. Arch Neurol 2010;67:3436.

17. Bähr O, Hermisson M, Rona S, et al. Intravenous and oral levetiracetam in patients with a suspected primary brain tumor and symptomatic seizures undergoing neurosurgery: The HELLO trial. Acta Neurochir 2012;154:22935. 
18. Van Breemen MSM, Rijsmann RM, Taphoorn MJB, Walchenbach R, Zwinkels H, Vecht CJ. Efficacy of antiepileptic drugs in patients with gliomas and seizures. $J$ Neurol 2009;256:151926.

19. Maschio M, Dinapoli L, Mingoia M, et al. Lacosamide as add-on in brain tumorrelated epilepsy: preliminary report on efficacy and tolerability. $J$ Neurol 2011;258:21004.

20. De Groot M, Aronica E, Heimans JJ, Reijneveld JC. Synaptic vesicle protein 2A predicts response to levetiracetam in glioma patients. Neurology 2011;77:5329.

21. Rogawski MA. Convection-enhanced delivery in the treatment of epilepsy. Neurotherapeutics 2009;6:34451.

22. Dalmau J, Gleichman AJ, Hughes EG, et al. Anti-NMDA-receptor encephalitis: case series and analysis of the effects of antibodies. Lancet Neurol 2008;7:10918.

23. Clusmann H, Schramm J, Kral T, et al. Prognostic factors and outcome after different types of resection for temporal lobe epilepsy. J Neurosurg 2002;97:113141.

24. Englot DJ, Berger MS, Barbaro NM, Chang EF. Predictors of seizure freedom after resection of supratentorial low-grade gliomas. J Neurosurg 2011;115:2404.

25. Luyken C, Blümcke I, Fimmers R, et al. The spectrum of long-term epilepsyassociated tumors: long-term seizure and tumor outcome and neurosurgical aspects. Epilepsia 2003;44:82230.

26. Chang EF, Potts MB, Keles GE, et al. Seizure characteristics and control following resection in 332 patients with low-grade gliomas. J Neurosurg 2008;108:22735. 
27. Sherman JH, Moldovan K, Yeoh HK, et al. Impact of temozolomide chemotherapy on seizure frequency in patients with low-grade gliomas. $J$ Neurosurg 2011;114:161721.

28. Krüger DA, Care MM, Holland K, et al. Everolimus for subependymal giant-cell astrocytomas in tuberous sclerosis. N Engl J Med 2010;363:180111.

29. Rosati A, Marconi S, Pollo B, et al. Epilepsy in glioblastoma multiforme: correlation with glutamine synthetase levels. J Neuro-Oncol 2009;93:31924.

30. Patt S, Labrakakis C, Bernstein M, et al. Neuron-like physiological properties of cells from human oligodendroglial tumors. Neuroscience 1996;71:60111.

31. Aronica E, Boer K, Becker A, et al. Gene expression profile analysis of epilepsyassociated gangliogliomas. Neuroscience 2008;151:27292.

32. Conti L, Palma E, Roseti C, et al. Anomalous levels of $\mathrm{Cl}(-)$ transporters cause a decrease of GABAergic inhibition in human peritumoral epileptic cortex. Epilepsia 2011;52:163544

33. Vezzani A, French J, Bartfai T, Baram TZ. The role of inflammation in epilepsy. Nat Rev Neurol 2011;7:3140. Epilepsy Res. 2011 Mar 3. [Epub ahead of print]

34. Liimatainen S, Lehtimäki K, Raitala A, et al. Increased indoleamine 2,3dioxygenase (IDO) activity in idiopathic generalized epilepsy. Epilepsy Res in press.

35. Opitz CA, Litzenburger UM, Sahm F, et al. An endogenous tumour-promoting ligand of the human aryl hydrocarbon receptor. Nature 2011;478:197203.

36. Eyal S, Yagen B, Sobol E, Altschuler Y, Shmuel M, Bialer M. The activity of antiepileptic drugs as histone deacetylase inhibitors. Epilepsia 2004;45:73744. 
37. Li XN, Shu Q, Su JM, Perlaky L, Blaney SM, Lau CC. Valproic acid induces growth arrest, apoptosis, and senescence in medulloblastomas by increasing histone hyperacetylation and regulating expression of p21Cip1, CDK4, and CMYC. Mol Cancer Ther 2005;4:191222.

38. Ecke I, Petry F, Rosenberger A, et al. Antitumor effects of a combined 5-aza-2deoxycytidine and valproic acid treatment on rhabdomyosarcoma and medulloblastoma in Ptch mutant mice. Cancer Res 2009;69:88795.

39. Oi S, Natsume A, Ito M, et al. Synergistic induction of NY-ESO-1 antigen expression by a novel histone deacetylase inhibitor, valproic acid, with 5-aza-2_deoxycytidine in glioma cells. J Neurooncol 2009;92:1522.

40. Fu J, Shao CJ, Chen FR, Ng HK, Chen ZP. Autophagy induced by valproic acid is associated with oxidative stress in glioma cell lines. Neuro-Oncol 2010;12:328340.

41. Ständer M, Dichgans J, Weller M. Anticonvulsant drugs fail to modulate chemotherapy-induced cytotoxicity and growth inhibition of human malignant glioma cells. J Neurooncol 1998;37:1918.

42. Lane AA, Chabner BA. Histone deacetylase inhibitors in cancer therapy. J Clin Oncol 2009;27:545968.

43. Bourg V, Lebrun C, Chichmanian RM, Thomas P, Frenay M. Nitrosoureacisplatin-based chemotherapy associated with valproate: increase of haematologic toxicity. Ann Oncol 2001;12:2179.

44. Weller M, Gorlia T, Cairncross JG, et al. Prolonged survival with valproic acid use in the EORTC/NCIC temozolomide trial for glioblastoma. Neurology $2011 ; 77: 115664$. 
45. Ward MM, Barbaro NM, Laxer KD, Rampil IJ. Preoperative valproate administration does not increase blood loss during temporal lobectomy. Epilepsia 1996;37:98101.

46. Anderson GD, Lin YX, Berge C, Ojemann GA. Absence of bleeding complications in patients undergoing cortical surgery while receiving valproate treatment. $J$ Neurosurg 1997;87:2526.

47. Maschio M, Dinapoli L, Sperati F, Fabi A, Pace A, Vidiri A, Muti P. Oxcarbazepine monotherapy in patients with brain tumor-related epilepsy: open-label pilot study for assessing the efficacy, tolerability and impact on quality of life. $J$ Neuro-Oncol 2012;106:6516.

48. Bobustuc GC, Baker CH, Limaye A, Jenkins WD, Pearl G, Avgeropoulos NG, Konduri SD. Levetiracetam enhances p53-mediated MGMT inhibition and sensitizes glioblastoma cells to temozolomide. Neuro-Oncol 2010;12:91727.

49. Weller M, Stupp R, Reifenberger G, Brandes AA, Van den Bent MJ, Wick W, Hegi ME. MGMT promoter methylation in malignant gliomas: ready for personalized medicine? Nat Rev Neurol 2010;6:3951.

50. Jaeckle KA, Ballman K, Furth A, Buckner JC. Correlation of enzyme-inducing anticonvulsant use with outcome of patients with glioblastoma. Neurology 2009;73:120713.

51. Rossetti AO, Stupp R. Correlation of enzyme-inducing anticonvulsant use with outcome of patients with glioblastoma. Neurology 2010;74:1329.

52. Stupp R, Mason WP, van den Bent MJ, et al. Radiotherapy plus concomitant and adjuvant temozolomide for glioblastoma. N Engl J Med 2005;352:98796. 
53. Gilbert MR, Wang M, Aldape KD, et al. RTOG 0525: a randomized phase III trial comparing standard adjuvant temozolomide (TMZ) with a dose-dense (dd) schedule in newly diagnosed glioblastoma (GBM). ASCO Meeting Abstracts 2011;29:2006.

54. Tsai HC, Wei KC, Tsai CN, et al. Effect of valproic acid on the outcome of glioblastoma multiforme. Br J Neurosurg 2011 Dec 15.

55. Oberndorfer S, Piribauer M, Marosi C, Lahrmann H, Hitzenberger P, Grisold W. P450 enzyme inducing and nonenzyme inducing antiepileptics in glioblastoma patients treated with standard chemotherapy. J Neurooncol 2005;72:25560.

56. Munster P, Marchion D, Bicaku E, et al. Clinical and biological effects of valproic acid as a histone deacetylase inhibitor on tumor and surrogate tissues: phase I/II trial of valproic acid and epirubicin/FEC. Clin Cancer Res 2009;15:248896.

57. Rocca A, Minucci S, Tosti G, et al. A phase I-II study of the histone deacetylase inhibitor valproic acid plus chemoimmunotherapy in patients with advanced melanoma. Br J Cancer 2009;100:2836.

58. Kaplan PW. Reproductive health effects and teratogenicity of antiepileptic drugs. Neurology 2004;63:S1323.

59. Jetter GM, Cavazos JE. Epilepsy in the elderly. Semin Neurol 2008;28:33641.

60. Elger CE, Schmidt D. Modern management of epilepsy: a practical approach. Epilepsy Behav 2008;12:501-39.

61. Tremont-Lukats IW, Ratilal BO, Armstrong T, Gilbert MR. Antiepileptic drugs for preventing seizures in people with brain tumors. Cochrane Database Syst Rev 2008;2:CD004424. 
62. Komotar RJ, Raper DM, Starke RM, Iorgulescu JB, Gutin PH. Prophylactic antiepileptic drug therapy in patients undergoing supratentorial meningioma resection: a systematic analysis of efficacy. J Neurosurg 2011;115:483-90.

63. Specchio LM, Beghi E. Should antiepileptic drugs be withdrawn in seizure-free patients? CNS Drugs 2004;18:20112. 
Table 1. AED profiles.

\begin{tabular}{|c|c|c|c|c|c|}
\hline & $\begin{array}{l}\text { Mode of } \\
\text { action }\end{array}$ & $\begin{array}{l}\text { Daily dose } \\
\text { (mg) }\end{array}$ & $\begin{array}{c}\text { Therapeutic } \\
\text { serum level } \\
(\mu \mathrm{g} / \mathrm{ml})\end{array}$ & Unwanted effects & Drug int \\
\hline Phenobarbital & $\begin{array}{l}\text { GABAergic, } \\
\text { prolonging } \\
\text { chloride } \\
\text { channel } \\
\text { opening } \\
\end{array}$ & $50-300$ & $10-40$ & $\begin{array}{l}\text { Sedation, cognition } \downarrow \text {, } \\
\text { allergy }\end{array}$ & $\begin{array}{l}\text { Enzyme } \\
\text { P450) }\end{array}$ \\
\hline Primidone & $\begin{array}{l}\text { GABAergic, } \\
\text { prolonging } \\
\text { chloride } \\
\text { channel } \\
\text { opening } \\
\end{array}$ & $500-1500$ & $5-15$ & Sedation, cognition $\downarrow$ & $\begin{array}{l}\text { Enzyme } \\
\text { P450) }\end{array}$ \\
\hline Clobazam & $\begin{array}{l}\text { GABAergic, } \\
\text { facilitating } \\
\text { chloride } \\
\text { channel } \\
\text { opening } \\
\end{array}$ & $10-30$ & $0.1-0.4$ & Sedation & $\begin{array}{l}\text { Sedative } \\
\text { medicati }\end{array}$ \\
\hline Clonazepam & $\begin{array}{l}\text { GABAergic, } \\
\text { facilitating } \\
\text { chloride } \\
\text { channel } \\
\text { opening }\end{array}$ & $0.5-4$ & $0.02-0.08$ & Sedation, cognition $\downarrow$ & $\begin{array}{l}\text { Sedative } \\
\text { medicati }\end{array}$ \\
\hline Phenytoin & $\begin{array}{c}\text { Sodium } \\
\text { channel } \\
\text { blocker (fast } \\
\text { inactivation) }\end{array}$ & $200-350$ & $10-20$ & $\begin{array}{l}\text { Dizziness, allergy, } \\
\text { hepatotoxicity, gingival } \\
\text { hyperplasia, cerebellar } \\
\text { atrophy, skin toxicity }\end{array}$ & $\begin{array}{l}\text { Enzyme } \\
\text { P450), ir } \\
\text { requirem }\end{array}$ \\
\hline Carbamazepine & $\begin{array}{c}\text { Sodium } \\
\text { channel } \\
\text { blocker (fast } \\
\text { inactivation) }\end{array}$ & $600-2000$ & $4-8$ & $\begin{array}{l}\text { Dizziness, nausea, } \\
\text { ataxia, hyponatremia, } \\
\text { leukopenia, } \\
\text { hepatotoxicity, skin } \\
\text { toxicity }\end{array}$ & $\begin{array}{l}\text { Enzyme } \\
\text { P450), ir } \\
\text { requirem }\end{array}$ \\
\hline
\end{tabular}




\begin{tabular}{|c|c|c|c|c|c|}
\hline Oxcarbazepine & $\begin{array}{l}\text { Sodium } \\
\text { channel } \\
\text { blocker (fast } \\
\text { inactivation) } \\
\end{array}$ & $900-2400$ & $10-35$ & $\begin{array}{l}\text { Hyponatremia, } \\
\text { leukopenia, skin toxicity }\end{array}$ & $\begin{array}{l}\text { Enzyme } \\
\text { P450), le }\end{array}$ \\
\hline Valproate & $\begin{array}{c}\text { Unclear, } \\
\text { inhibition of ion } \\
\text { channels (?), } \\
\text { promotion of } \\
\text { GABA } \\
\text { signaling (?) } \\
\end{array}$ & $1200-2400$ & $50-100$ & $\begin{array}{l}\text { Tremor, weight } \uparrow \\
\text { coagulation disorders, } \\
\text { thrombocytopenia, } \\
\text { teratogenicity }\end{array}$ & $\begin{array}{l}\text { Multiple } \\
\text { glucuron } \\
\text { hydrolas } \\
\text { increa } \\
\text { chemoth }\end{array}$ \\
\hline Lamotrigine & $\begin{array}{l}\text { Sodium } \\
\text { channel } \\
\text { blocker (fast } \\
\text { inactivation) }\end{array}$ & $100-300$ & $2-15$ & $\begin{array}{l}\text { Skin toxicity, tremor, } \\
\text { sedation (rare) }\end{array}$ & $\begin{array}{l}\text { Carbami } \\
\text { phenoba } \\
\text { reduce li } \\
\text { whereas } \\
\text { lamotriqi }\end{array}$ \\
\hline Gabapentin & $\begin{array}{c}\text { Calcium } \\
\text { channel } \\
\text { blocker (high } \\
\text { voltage), } \\
\text { GABA agonist } \\
(?) \\
\end{array}$ & $900-3000$ & $2-20$ & Sedation, weight gain & $\begin{array}{l}\text { Limits bi } \\
\text { and may } \\
\text { morphin }\end{array}$ \\
\hline Pregabaline & $\begin{array}{c}\text { Calcium } \\
\text { channel } \\
\text { blocker (high } \\
\text { voltage) }\end{array}$ & $150-600$ & $2-5$ & Sedation, weight gain & No relev \\
\hline Topiramate & \begin{tabular}{|c|} 
Multiple: \\
sodium \\
channel \\
blocker, GABA \\
agonist, \\
NMDA \\
receptor \\
antagonist \\
\end{tabular} & $50-200$ & $2-20$ & $\begin{array}{l}\text { Sedation, fatigue, } \\
\text { inappetence, weight } \\
\text { loss, psychosis }\end{array}$ & $\begin{array}{l}\text { May red } \\
\text { contrace }\end{array}$ \\
\hline Levetiracetam & $\begin{array}{l}\text { SV2A receptor } \\
\text { binding }\end{array}$ & $1000-3000$ & $3-30$ & $\begin{array}{l}\text { Sedation (rare), } \\
\text { psychiatric side effects }\end{array}$ & No relev \\
\hline Lacosamide & Sodium & $100-400$ & $10-20$ & Dizziness, nausea, & No relev \\
\hline
\end{tabular}




\begin{tabular}{|c|c|c|c|c|c|}
\hline & $\begin{array}{c}\text { channel } \\
\text { blocker (slow } \\
\text { inactivation), } \\
\text { CRMP2 } \\
\text { binding } \\
\end{array}$ & & & $\begin{array}{l}\text { headache, cognition } \downarrow \text {, } \\
\text { skin toxicity }\end{array}$ & \\
\hline Zonisamide & Multiple & $300-500$ & $20-30$ & $\begin{array}{l}\text { Dizziness, ataxia, } \\
\text { anorexia }\end{array}$ & $\begin{array}{l}\text { No or mi } \\
\text { cytochro } \\
\text { may red }\end{array}$ \\
\hline Tiagabine & $\begin{array}{c}\text { GABAergic, } \\
\text { blocks } \\
\text { synaptic } \\
\text { GABA uptake }\end{array}$ & $15-70$ & $0.02-0.08$ & Dizziness, fatigue & $\begin{array}{l}\text { Levels a } \\
\text { cotreatm }\end{array}$ \\
\hline Vigabatrin & $\begin{array}{l}\text { GABAergic, } \\
\text { inhibits GABA } \\
\text { transaminase }\end{array}$ & $200-300$ & $0.8-36$ & $\begin{array}{l}\text { Visual field defects, } \\
\text { fatigue, sedation }\end{array}$ & $\begin{array}{l}\text { Reduces } \\
25 \%\end{array}$ \\
\hline
\end{tabular}

CRMP2, collapsin response mediator protein-2; GABA, $\gamma$-aminobutyric acid; NMDA, Nmethyl-D-asparate; SV2A, synaptic vesicle $2 A$; 
Table 2. Commonly used anti-cancer drugs negatively affected by EI-AED comedication.

\begin{tabular}{|l|l|}
\hline Alkylating agents & $\begin{array}{l}\text { Nitrosoureas: carmustine (BCNU), lomustine } \\
\text { (CCNU), nimustine (ACNU), fotemustine; } \\
\text { thiotepa; cyclophosphamide; ifosfamide }\end{array}$ \\
\hline Mitotic inhibitors & Vinca-alcaloids: vincristine, vinorelbine; \\
paclitaxel, docetaxel \\
\hline DNA-damaging agents & irinotecan, topotecan, etoposide, adriamycin \\
\hline Antimetabolites & \\
\hline Signal transduction inhibitors & Imatinib, erlotinib, gefinitib, sorafenib, \\
\hline Proteasome inhibitors & temsirolimus, everolimus, vemurafenib \\
\hline
\end{tabular}


Table 3. Frequently asked questions (FAQ) in the context of epilepsy and cancer.

\begin{tabular}{|c|c|}
\hline $\begin{array}{l}\text { Should all brain tumor patients } \\
\text { receive } A E D ?\end{array}$ & $\begin{array}{l}\text { There is no evidence that primary prophylaxis with AED decrease } \\
\text { ever seizure in brain tumor patients. }{ }^{13,61,62} \text { This statement is base } \\
\text { examining phenobarbital, phenytoin, or valproic acid and may no } \\
\text { extrapolated to other AED. }\end{array}$ \\
\hline $\begin{array}{l}\text { Should all brain tumor patients } \\
\text { who undergo a craniotomy receive } \\
A E D ?\end{array}$ & $\begin{array}{l}\text { No, there is also no evidence that primary prophylaxis with } A E[ \\
\text { of a first-ever seizure in brain tumor patients undergoing cranio }\end{array}$ \\
\hline $\begin{array}{l}\text { Should I take my patient off } A E D \text { if } \\
\text { these were instituted without good } \\
\text { reason? }\end{array}$ & $\begin{array}{l}\text { Yes, but slowly not to provoke seizures, and specific attention t } \\
\text { pharmacokinetics of co-medications is warranted when El-AED }\end{array}$ \\
\hline $\begin{array}{l}\text { Should all brain tumor patients } \\
\text { receive } A E D \text { after the first seizure? }\end{array}$ & $\begin{array}{l}\text { Yes, because epilepsy is highly likely to be symptomatic and re } \\
\text { further seizures until the tumor has been adequately treated. }\end{array}$ \\
\hline $\begin{array}{l}\text { How long should brain tumor } \\
\text { patients with a presenting seizure, } \\
\text { who remain seizure-free after } \\
\text { surgery, receive AED? }\end{array}$ & $\begin{array}{l}\text { In the absence of randomized trial data, tapering and discontint } \\
\text { weeks is recommended, depending on histology and tumor cor } \\
\text { seizures in this patient population is strongly associated with tu } \\
\text { progression. }\end{array}$ \\
\hline $\begin{array}{l}\text { How long should brain tumor } \\
\text { patients, who experience seizures } \\
\text { after surgery, be maintained on } \\
\text { anticonvulsants? } \\
\text { How long should brain tumor } \\
\text { patients, who experience seizures } \\
\text { and never had surgery, be } \\
\text { maintained on anticonvulsants? }\end{array}$ & $\begin{array}{l}\text { The occurrence of seizures later than } 48-72 \mathrm{~h} \text { after surgery, or } \\
\text { in brain tumor patients with no other predisposing factor usually } \\
\text { for long-term AED treatment. Often patients will never become } \\
\text { experience only a reduction in seizure frequency and severity. } \\
\text { and eventually discontinue AED requires the consideration of } v \\
\text { factors, notably tumor control. The risks of recurrent seizures, } \\
\text { bony metastases or anticoagulation, need to be weighed again } \\
\text { receiving AED. In a general population of patients with (largely) } \\
\text { free from seizures for } 2 \text { years, the rate of relapse within the firs } \\
\text { withdrawal is in the range of } 50 \%, 63 \text { and is probably higher in b } \\
\text { with symptomatic epilepsy. The social implications of seizure re } \\
\text { driving, work, and leisure activities, need to be considered, too. }\end{array}$ \\
\hline $\begin{array}{l}\text { Which AED is best for cancer } \\
\text { patients with epilepsy? }\end{array}$ & $\begin{array}{l}\text { EI-AED should be avoided with few exceptions. Valproic acid a } \\
\text { be dosed quickly and intravenously. }{ }^{16,17} \text { Lamotrigine needs to } \\
\text { mainly due to the allergic potential but has otherwise favourabl } \\
\text { and efficacy. }\end{array}$ \\
\hline $\begin{array}{l}\text { What is the role of serum level } \\
\text { monitoring in cancer patients on } \\
A E D ?\end{array}$ & $\begin{array}{l}\text { Routine monitoring of serum levels of AED is not required and } \\
\text { available for all agents described in Table } 2 \text {. Rationales includ } \\
\text { patients' compliance, (ii) to assess whether physical or mental } \\
\text { may represent AED toxicity and (iii) to assess whether approp }\end{array}$ \\
\hline
\end{tabular}




\begin{tabular}{|l|l|}
\hline & achieved in AED-unresponsive patients who continue to experier \\
\hline $\begin{array}{l}\text { Which of my cancer patients } \\
\text { require monitoring by EEG? }\end{array}$ & $\begin{array}{l}\text { Monitoring by EEG is not required for the majority of cancer patie } \\
\text { is of value in the initial work-up of suspected seizures and if there } \\
\text { about continuous seizure activity in the course of disease. The E } \\
\text { important role in the management of patients with biologically ber } \\
\text { tumors where epilepsy is the major burden of the disease. }\end{array}$ \\
\hline $\begin{array}{l}\text { Which of my cancer patients } \\
\text { should be allowed to drive? }\end{array}$ & $\begin{array}{l}\text { Country-specific regulations need to be considered. Seizure cont } \\
\text { control are required. However, it is important to recognize that tur } \\
\text { neurological deficits other than seizures, such as hemianopia or } \\
\text { may interfere with the competence to drive. We recommend not t } \\
\text { an interval following brain surgery or when there is overt brain tur } \\
\text { irrespective of a positive or negative seizure history. Further, driv } \\
\text { permitted during tapering and withdrawing AED. }\end{array}$ \\
\hline
\end{tabular}

